\title{
Activity Dependence of Cortical Axon Branch Formation: A Morphological and Electrophysiological Study Using Organotypic Slice Cultures
}

\author{
Naofumi Uesaka, ${ }^{1}$ Satoshi Hirai, ${ }^{1}$ Takuro Maruyama, ${ }^{1}$ Edward S. Ruthazer, ${ }^{2}$ and Nobuhiko Yamamoto ${ }^{1}$ \\ ${ }^{1}$ Neuroscience Laboratories, Graduate School of Frontier Biosciences, Osaka University, Osaka 565-0871, Japan, and ${ }^{2}$ Department of Neurology and \\ Neurosurgery, Montreal Neurological Institute, McGill University, Montréal, Québec, H3A 2B4 Canada
}

\begin{abstract}
The influence of neuronal activity on cortical axon branching was studied by imaging axons of layer $2 / 3$ neurons in organotypic slice cultures of rat visual cortex. Upper layer neurons labeled by electroporation of plasmid encoding yellow fluorescent protein were observed by confocal microscopy. Time-lapse observation of single-labeled axons showed that axons started to branch after $8-10 \mathrm{~d}$ in vitro. Over the succeeding 7-10 d, branch complexity gradually increased by both growth and retraction of branches, resulting in axon arbors that morphologically resembled those observed in 2- to 3-week-old animals. Electrophysiological recordings of neuronal activity in the upper layers, made using multielectrode dishes, showed that the frequency of spontaneous firing increased dramatically $\sim 10 \mathrm{~d}$ in vitro and remained elevated at later stages. To examine the involvement of spontaneous firing and synaptic activity in branch formation, various blockers were applied to the culture medium. Cultures were silenced by TTX or by a combination of APV and DNQX but exhibited a homeostatic recovery of spontaneous activity over several days in the presence of blockers of either NMDA-type or non-NMDA-type glutamate receptors alone. Axonal branching was suppressed by TTX and AMPA receptor blockade but not by NMDA receptor blockade. We conclude that cortical axon branching is highly dynamic and that neural activity regulates the early developmental branching of upper layer cortical neurons through the activation of AMPA-type glutamate receptors.
\end{abstract}

Key words: cortex; development; axon; activity; branching; culture

\section{Introduction}

During neural circuit formation, an intriguing axonal behavior is the formation of elaborate branches in target regions. This developmental event permits neurons to make extensive synaptic connections selectively with appropriate target cells.

In most vertebrate species, it is believed that there are at least two modes in the morphological development of axons (Acebes and Ferrus, 2000). The first is stereotyped branching, as is found in the topographic- and layer-specific elaboration of retinotectal projections and cortical connections (Sanes and Yamagata, 1999; Yamamoto et al., 2002; McLaughlin et al., 2003a). In these systems, early axonal branching is regulated by branch-promoting and -inhibiting factors expressed in specific locations and stages (Yamagata and Sanes, 1995; Inoue and Sanes, 1997; Castellani et al., 1998; Yamamoto et al., 2000; Yates et al., 2001; Hindges et al., 2002; Mann et al., 2002; Sakurai et al., 2002; McLaughlin et al., 2003b).

The other mode involves modification by neuronal activity.

Received April 1, 2004; revised Nov. 1, 2004; accepted Nov. 1, 2004.

This work was supported by Grants-in-Aid for Scientific Research 11680788 and 12050227 from the Japanese Ministry of Education, Culture, Sports, Science and Technology and by Human Frontier Science Project RGP0107/ 2001. We thank Maki Nishiwaki for assistance in labeling with fluorescent protein.

Correspondence should be addressed to Dr. Nobuhiko Yamamoto, Neuroscience Laboratories, Graduate School of Frontier Biosciences, Osaka University, Suita, Osaka 565-0871, Japan. E-mail: nobuhiko@fbs.osaka-u.ac.jp. DOI:10.1523/JNEUROSCI.3855-04.2005

Copyright $\odot 2005$ Society for Neuroscience $\quad$ 0270-6474/05/250001-09\$15.00/0
Both sensory-evoked and spontaneous firing have been demonstrated to influence wiring patterns in the brain (Hubel et al., 1977; Reh and Constantine-Paton, 1985; Shatz and Stryker, 1988; Hata and Stryker, 1994; Penn et al., 1998). Several studies have indicated that neural activity affects individual axonal branching in vivo (Udin, 1983; Sretavan et al., 1988; Cline and ConstantinePaton, 1990; Antonini and Stryker, 1993, 1996; O'Rourke et al., 1994; Antonini et al., 1999; Cohen-Cory, 1999; Hata et al., 1999; Ruthazer et al., 2003). However, little is known about the mechanisms by which neural activity influences axonal branching.

To explore the role of neural activity on axonal branching, we have focused on the development of horizontal axons in the mammalian neocortex. Horizontal axons are long-range axon collaterals that horizontally run in layer $2 / 3$ and form branches in the same layer (Gilbert and Wiesel, 1979; Rockland and Lund, 1982; Burkhalter and Charles, 1990; McGuire et al., 1991; Lohmann and Rorig, 1994). It has been reported that these axon arbors develop during postnatal stages by growth and retraction (Callaway and Katz, 1990; Durack and Katz, 1996). Moreover, it is likely that neuronal activity is involved in this process, because the organization of these connections is altered by deprivation of visual experience (Callaway and Katz, 1991; Lowel and Singer, 1992) and by blockade of action potentials (Ruthazer and Stryker, 1996).

In the present study, we examined the role of neuronal activity in branching of horizontal axons using organotypic slice cultures, 
in which cortical cytoarchitecture and fine structures such as axonal projections and dendritic morphology are preserved (Yamamoto et al., 1992; McAllister et al., 1995; Dantzker and Callaway, 1998). Development of axonal morphology over many days was studied by time-lapse confocal imaging of individual yellow fluorescent protein (YFP)-transfected axons. The influence of neuronal activity on axonal branching was further studied by pharmacological manipulation of glutamatergic transmission and action potential firing, monitored by electrophysiological recordings from multielectrode arrays on which the cultures were grown. The results suggest that neuronal activity contributes to the development of horizontal axon branching by activating synaptic transmission through non-NMDA receptors.

\section{Materials and Methods}

Organotypic slice culture. Sprague Dawley rats were used for this study. The first $24 \mathrm{hr}$ after birth was referred to as postnatal day 0 (P0). Coronal slices were dissected from P0 or P1 rat occipital cortex and were cultured using organotypic culture techniques, as reported previously (Yamamoto et al., 1989, 1992). In brief, these slices were cultured in serum-free, hormone-supplemented medium on culture membranes (Millicell-CM PICMORG50; Millipore, Bedford, MA) that were coated with a collagen solution prepared from rat tails. To monitor neuronal activity, cortical slices were grown on multielectrode culture dishes (MEDs) (Alpha MED Sciences, Tokyo, Japan) that were coated with collagen. In both cases, the cultures were maintained at $37^{\circ} \mathrm{C}$ in an environment of humidified $95 \%$ air and $5 \% \mathrm{CO}_{2}$.

Axon labeling by electroporation. To label cortical axons, we developed local electroporation and single-cell electroporation methods. In local electroporation, a relatively large number of cells were transfected but localized in a small region $(\sim 0.2 \mathrm{~mm}$ in diameter $)$. In the single-cell electroporation method, individual or, at most, a small number of cells were transfected and clearly distinguishable.

A plasmid containing the coding region of enhanced YFP (EYFP) (pCAGGS:EYFP; a generous gift from Dr. Y. Hatanaka, University of Tsukuba, Tsukuba, Japan) was used for the electroporation (Niwa et al., 1991). The plasmid was isolated (Plasmid Maxi kit; Qiagen, Tokyo, Japan) and resuspended at concentrations of $1.0-1.5 \mathrm{mg} / \mathrm{ml}$ in Hanks' solution. In both methods, electroporation was performed after 5-6 d in vitro (DIV). Cellular morphology was observed from a few days to $>1$ week after transfection.

For local electroporation, a glass micropipette (tip diameter, 50-100 $\mu \mathrm{m}$ ) was filled with the plasmid solution. The tip of the micropipette was placed between 100 and $300 \mu \mathrm{m}$ from the pial surface of cortical slices with a micromanipulator (MO-10; Narishige, Tokyo, Japan). Then, a pair of tungsten electrodes ( $\sim 300 \mu \mathrm{m}$ apart) was positioned on both sides of the tip of the micropipette. After pressure injection of the plasmid-containing solution, voltage pulses $(100 \mathrm{~V}$; pulse duration, 5 msec; interval, $1 \mathrm{sec} ; 10$ times) were delivered with a square-pulse electroporator (CUY-20; BEX, Tokyo, Japan).

The single-cell electroporation method was modified from Haas et al. (2001). Single-cell electroporation was accomplished using a glass micropipette (tip diameter, $30-50 \mu \mathrm{m}$ ) filled with plasmid-containing solution. A silver wire $(0.2 \mathrm{~mm}$ diameter $)$ was placed inside the micropipette in contact with the DNA solution. The tip was then placed on the culture surface. Current pulses, generated by a stimulator (Master 8; A.M.P.I.,, Jerusalem, Israel) and a biphasic isolator (BSI-2; BAK Electronics, Germantown, MD), were delivered between the micropipette and a silver wire ground electrode. For delivery of negatively charged DNA, the silver wire inside the micropipette was connected to the negative terminal (anode) of the isolator, and the ground electrode was connected to the positive terminal (cathode). The current passing through the micropipette was monitored across a resistor $(100 \Omega)$ in series. The electroporation pulse parameter was three to five trains of 200 square pulses of 1 msec duration at $200 \mathrm{~Hz}$ and of $100-150 \mu \mathrm{A}$ amplitude.

The somata, dendrites, and axons of individual or a small number of cells were clearly labeled by single-cell electroporation. The local electro- poration method also labeled cells with axons that traveled horizontally from the upper layers but did not always permit identification of the soma of each axon because of the dense cluster of labeled cells resulting from this method. In both methods, single-labeled horizontal axons that were distinguishable from the others were selected for analysis.

To observe axonal projection pattern in vivo, upper layer cells were transfected similarly with the YFP vector in cortical slices immediately after dissection. The slices were then cultured for $24 \mathrm{hr}$, which allowed the protein to be synthesized and diffused into processes. This method enabled us to observe cellular morphology at P7 acute slices but not for older animals.

Confocal imaging and quantitative analysis of labeled axon. Cells labeled with YFP were observed using a laser-scanning confocal microscope (MRC-600; Bio-Rad, Tokyo, Japan). YFP fluorescence remained high for $>1$ week, even with repeated imaging. An objective lens with long working distance $(10 \times, 20 \times$, or $40 \times$; working distance, 5-6 mm) was used. The confocal microscope was equipped with an argon laser (excitation wavelength, $488 \mathrm{~nm}$ ) and a filter set for fluorescein isothiocyanate. A neutral density filter (1-10\% transmittance) was placed in the path of the laser to reduce the intensity of excitation and minimize photodynamic damage produced by the excitation beam. Transmitted light images were also collected to locate the pial surface of the cortical slice. A total of 2-20 optical sections were sampled at different depths (2-10 $\mu \mathrm{m}$ interval). Each image was averaged three or four times to increase the signal/noise ratio. At the end of the experiment, images were taken at lower magnification ( $4 \times$ objective) to determine the locations of axons in the cortical explants.

Labeled axons were reconstructed using NIH Image. They were drawn only if they met the following criteria: (1) they elongated between 100 and $400 \mu \mathrm{m}$ from the pial surface and had a length of $\geq 500 \mu \mathrm{m}$; (2) they originated from transfected cell clusters or single-labeled pyramidal cells within 100-300 $\mu \mathrm{m}$ from the pial surface; (3) they were brightly labeled and readily distinguishable from others; and (4) they appeared healthy (as determined by the absence of notable membrane blebbing in the cell body, axons, or dendrites). All measurements of axonal morphology, such as branch length and total arbor length, were performed using custom NIH Image software macros. Small processes $(<5 \mu \mathrm{m})$ from the axon shaft were excluded from the analysis, because lamellipodia- or varicosity-like structures within this size range were often observed. The following parameters were measured: the number of branch points; the axon length defined as the distance from the cell body to the most distal branch tip within upper layers; the branch point density of the arbor (number of branch points per total arbor length); the lengths of individual branch tip segments measured from the branch tips to their nearest branch points; and the order of branch tip segments. For the order of branch tip segments, the unbranched axon has a branch order of zero. Branches originating from the first branch point have a branch order of 1 ; those branches from the next branch point to the first branch point have branch order of 2; and so on. The maximum order was measured.

Time-lapse imaging. To observe dynamics of axon branching, the culture dishes (Millicell-CM PICMORG50; Millipore) were mounted on a stage of the confocal microscope (Yamamoto et al., 1997). Labeled axons were observed quickly, and then the cultures were put back into the incubator. These observations were performed every $24 \mathrm{hr}$ for 3-7 d. Afterward, similar quantitative analysis was performed (see above). Branch dynamics (growth or retraction) were measured by comparing branches at a given time point with those after $24 \mathrm{hr}$. The branches that grew or retracted $<5 \mu \mathrm{m}$ for $24 \mathrm{hr}$ were classified as stable.

Recording and quantitative analysis of spontaneous activity using MEDs. To record spontaneous activity of cortical cells, we used techniques similar to those used for organotypic hippocampal slice cultures (Shimono et al., 2002). Spontaneous activity in cultures was recorded through MEDs twice per day at $10 \mathrm{~min}$ intervals for $3 \mathrm{~min}$ or once per day for $15 \mathrm{~min}$. MEDs have an array of 64 planar microelectrodes arranged in an $8 \times 8$ pattern. The size of the recording electrodes is $50 \times 50 \mu \mathrm{m}$ with $\sim 22 \mathrm{k} \Omega$ input resistance. The extracellular voltages at the electrodes were amplified by a factor of 10 using the 8-Channel Head Amplifier (SH-MED8; Alpha MED Sciences), further amplified by the 8-Channel main amplifier (bandwidth filter, 0.1-20 kHz; SU-MED8; Alpha MED Sciences), 
and digitized at $5 \mathrm{kHz}$ by a 12-bit data acquisition board (DigiData 1200; Axon Instruments, Foster City, CA). The digitized data were analyzed using AxoScope software (Axon Instruments).

During electrophysiological recording, the slices cultured on the MED probe were placed in a small $\mathrm{CO}_{2}$ incubator (model 4020; Asahi Lifescience, Tokyo, Japan) with humidified $5 \% \mathrm{CO}_{2}$ and $95 \%$ air at $37^{\circ} \mathrm{C}$. Potentials were recorded at the electrodes positioned between 100 and $300 \mu \mathrm{m}$ from the pial surface. An electrode far from the slice was used as a reference electrode. The noise level on each electrode was within the range of $10-20 \mu \mathrm{V}$. The frequency of spontaneous firing activity was quantified with Axograph software (Axon Instruments). Negative potentials with amplitudes above a set threshold were counted as one spike. The threshold of 1.5 times the maximal amplitude of the baseline noise $(20 \mu \mathrm{V})$ was used.

Pharmacological treatments. To manipulate firing and synaptic activity, culture medium containing the following drugs was used between 7 and 15 DIV: D-APV $(100 \mu \mathrm{M}),(+)$-5-methyl-10,11-dihydro-5H-dibenzo [a,d] cyclohepten-5,10-imine maleate (MK801; $10 \mu \mathrm{M})$, DNQX (20 $\mu \mathrm{M}),( \pm)$ 4-(4-aminophenyl)-1,2-dihydro-1-methyl-2-propylcarbamoyl-6,7-methylenedioxyphthalazine (SYM2206; $100 \mu \mathrm{M}),(\alpha S)-\alpha$-amino-3-\{(4-carboxyphenyl)methyl \}-3,4-dihydro-5-iodo-2,4-dioxo-1(2H)-pyrimidinepropanoic acid (UBP301; $100 \mu \mathrm{M}$; Tocris Cookson, Bristol, UK), and TTX (100 nм; Seikagaku-Kogyo, Toyko, Japan). Drug-containing media were exchanged every other day.

Statistical analysis. All statistical values obtained from the morphological and electrophysiological experiments were presented as mean \pm SEM. For all features measured, evaluation of the differences among groups was obtained by comparing groups two at a time, using the MannWhitney $U$ test for nonparametric statistical analysis.

Histology. The cultures were fixed with $4 \%$ paraformaldehyde in $0.1 \mathrm{M}$ phosphate buffer after the observations and kept in 30\% sucrose in PBS. Cultures were embedded on an agar block ( $4 \%$ agar in PBS), cut into 20 $\mu \mathrm{m}$ frozen sections, and stained with methylene blue to compare cell density and size in the cortical explants.

\section{Results}

\section{Cellular morphology of upper layer cells labeled with YFP}

Horizontally extending axons in the upper layers of the visual cortex were studied in organotypic slice cultures. Rat cortical neurons that are destined for layer $2 / 3$ are still migrating at $\mathrm{P} 0$, when cortical slices were transferred to the culture conditions. Previous studies have demonstrated that radial migration takes place in vitro (Yamamoto et al., 1992; Roberts et al., 1993) and that laminar configuration is settled approximately 1 week in vitro, which resembles the in vivo situation (Yamamoto et al., 1992). Therefore, cortical cells in the upper layers (100-300 $\mu \mathrm{m}$ from the pial surface) were transfected after 5-6 d in culture with pCAGGS:EYFP to visualize axons originating from these neurons (see Materials and Methods). As shown in Figure 1, $A$ and $C$, axons from the upper layers were labeled clearly as well as pyramidal-shaped soma and dendrites even $>1$ week after electroporation. The primary axons run radially toward the white matter side, whereas collaterals elongated in the upper and deep layers. Thus, the projection pattern of such cells was notably similar to that described for layer $2 / 3$ pyramidal cells in the cortex of rodents and the higher mammals, although the number of branches is much larger in the higher mammals (Gilbert and Wiesel, 1979; Rockland and Lund, 1982; Burkhalter and Charles, 1990; McGuire et al., 1991; Lohmann and Rorig, 1994; Durack and Katz, 1996; van Brederode et al., 2000).

\section{Branching of horizontal axons}

Branching of horizontal axons was studied after 1-3 weeks in culture. Most axons extended within the upper layers without forming extensive branches for the first week in vitro. This was also true for horizontal axon morphology in vivo during devel-
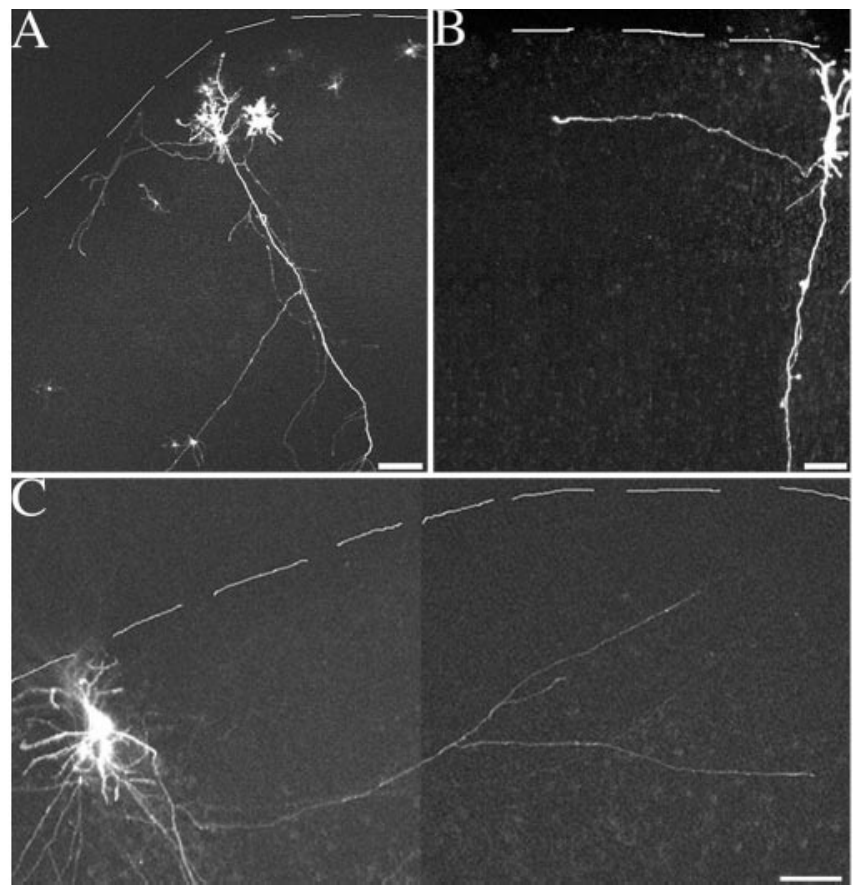

Figure 1. Cellular morphology of cortical upper layer neurons. A, Low-power fluorescence photomicrographs of a slice cultured from a PO rat showing a typical YFP-labeled neuron after 2 weeks in vitro. An upper layer neuron displays a descending axon that branches several times with collaterals of the axon extending within upper layers. B, Fluorescence photomicrographs of slice culture from a P7 rat showing a YFP-labeled cell $24 \mathrm{hr}$ after transfection. C, Another example of a YFP-labeled neuron in the upper layers after $10 \mathrm{DIV}$. The dashed line indicates the pial surface of the cortical explants. Scale bars: $A, 200 \mu \mathrm{m} ; B, C, 100 \mu \mathrm{m}$.

opment. YFP labeling in acute cortical slices, which were dissected from 7-d-old rat visual cortex, demonstrated that horizontal axons had no branches at this stage (Fig. $1 B$ ). After 8-10 DIV, branches emerged and the primary axons stopped growing in most cases (Fig. 1C). Afterward, axonal arbors became larger and more complex. Time-lapse imaging further demonstrated a dynamic feature of branch formation (Fig. 2A). Some branches were dynamic, either growing or retracting between imaging sessions, whereas others were relatively stable. Some varicosities were also found along the axons, and their positions appeared to change during culturing.

Axonal arbor dynamics were evaluated by measuring the number of branches that were added or eliminated and the number of preexisting branches that lengthened or shortened compared with the previous day. Throughout the observation period, the percentage of growing branches, which included newly added branches and lengthened branches, tended to be higher than that of retracting and eliminated branches (Fig. $2 B$ ). After $\sim 2$ weeks in vitro, $\sim 20 \%$ of all branches had become stable. Thus, branching of horizontal axons in cortical upper layers was a continuous and highly dynamic process during this second week in vitro but was relatively stable afterward.

Based on these developmental observations, branching parameters such as the number of branches were observed after 13-15 d in vitro, when stable branches appeared frequently (Fig. $2 B$ ). Figure 3 shows several examples of horizontal axons traced after 13-15 $\mathrm{d}$ in vitro. The mean number of branch points per axons was $4.5 \pm 0.6(n=42)$, ranging from 0 to 17 branch points per axon. The average length of horizontal axons in culture was $1540 \pm 236 \mu \mathrm{m}(n=12$ axons traced back perfectly to the cell body). These values were comparable with those for horizontal 
axons in 2- to 3-week-old rat cortex (Lohmann and Rorig, 1994; van Brederode et al., 2000). Thus, the branch morphology of horizontal axons closely resembled that of arbors in vivo.

\section{Spontaneous firing in cultured cortex}

Because there are no extrinsic inputs to these cultured cortical explants, any neuronal activity must arise from the spontaneous firing of neurons in the culture. Spontaneous firing was observed as singleunit or field-potential activity (Fig. 4A, $B$ ). The single-unit activity lasted a few milliseconds in duration and most likely represents action potentials in individual cells (Fig. 4A). The field-potential activity was a negative potential of $\sim 100 \mathrm{msec}$ in duration and variable amplitude (Fig. $4 B$ ) and is probably caused primarily by synchronized firing and synaptic potentials of many cells. In addition, bursting activity was often observed (burst duration, 0.2-2 sec; burst interval, $1-60 \mathrm{sec}$; firing frequency, 3-30 Hz). This burst activity was detected as single units on a background of field-potential activity. To investigate the spatial distribution of spontaneous patterns of activity in cortical slices, activity was simultaneously recorded at several locations between 100 and $300 \mu \mathrm{m}$ from the pial surface. Spontaneous firing was highly synchronized among multiple recording sites tested (data not shown) and occurred to a similar extent in every location. Fundamentally, synchronized activity was found across the entire cortical slice. Therefore, the activity recorded with one or two electrodes around the upper layers was considered to reflect the typical activity of cortical cells in each slice.

Development of spontaneous activity was examined by monitoring the same samples repeatedly over many days. Figure $4 C$ shows the activity recorded after 6, 10, and 13 DIV. Spontaneous activity was infrequent before 1 week in vitro but was prominent at later times. In most cases, the spontaneous activity appeared rhythmically with a long silent period, which was variable among samples. To quantify the activity levels in the organotypic cultures, the number of negative potentials, including field potentials, was counted for 6-15 min per day. As shown in Figure $4 D$, the mean firing rate in the early stages was quite low $(0.18 \pm 0.10$ $\mathrm{Hz} ; n=10$ for $5-8$ DIV) but increased strikingly by 11 DIV and further increased and was maintained at later stages (1.27 \pm 0.19 $\mathrm{Hz} ; n=15$ for 9-14 DIV).

\section{The effects of spontaneous activity in axonal branching}

The above results suggest that the developmental time course of spontaneous activity correlates with that for branch formation, raising the possibility that spontaneous activity might affect axonal branching. First, the onset of spontaneous firing preceded the emergence of horizontal axon branching by 1 or $2 \mathrm{~d}$ (compare Figs. $2 \mathrm{~B}, 4 \mathrm{D})$. Second, the amount of branch growth correlated with the increase of spontaneous firing. The growth ratio, defined as the ratio of the number of growing branches to the number of retracting branches, was moderately correlated with the increased level of spontaneous activity $1 \mathrm{~d}$ before $(r=0.43)$.

To further test how firing activity influences branch formation, blockers of action potential firing or glutamatergic synaptic
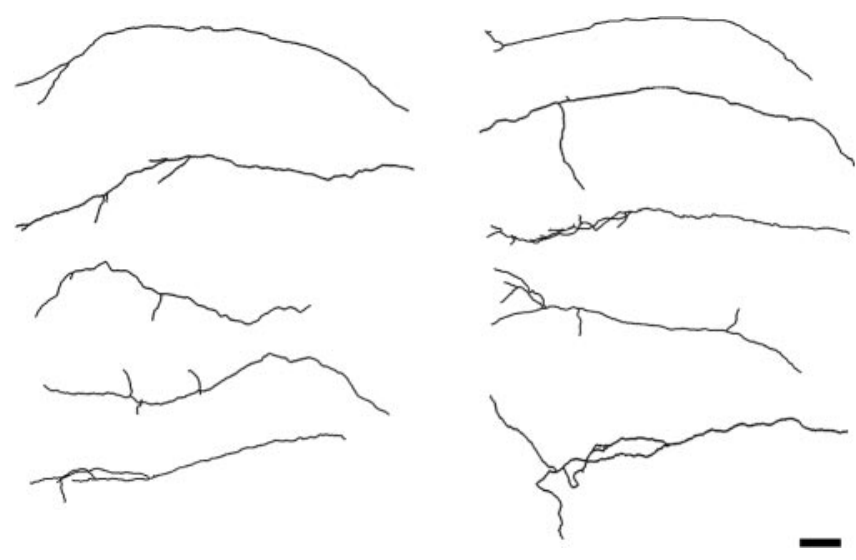

Figure 3. Ten examples of axonal branching of upper layer neurons after 2 weeks in vitro. Tracings were made of YFP-labeled neurons. Scale bar, $100 \mu \mathrm{m}$.

transmission were applied to the culture medium during the second week in vitro, when branch elaboration normally occurs.

The efficacy of chronically applied drugs was examined by recording changes in activity through the MED electrodes. The addition of TTX or APV/DNQX to the culture medium quickly caused a complete cessation of spontaneous activity. This effect persisted to the final day of recording (Fig. 5). Likewise, spontaneous activity was diminished after the addition of DNQX or APV but began to reappear after a few days. Although firing rates further increased at later stages, the activity between 8 and 14 DIV did not differ substantially from that in the control cultures (Fig. 5B) (control: $1.1 \pm 0.17 \mathrm{~Hz}, n=15$; DNQX: $1.1 \pm 0.50 \mathrm{~Hz}, n=$ $4, p>0.1$; APV: $1.7 \pm 0.32 \mathrm{~Hz}, n=4, p>0.1)$. The mechanism for this recovery is not known, but homeostatic regulation including receptor expression may account for this phenomenon (Turrigiano et al., 1998; Luthi et al., 2001). However, spontaneous activity in the presence of DNQX or APV each showed distinct patterns. Spontaneous activity under chronic DNQX application tended to show similar but slightly longer burst durations than controls (burst duration, $0.4-3 \mathrm{sec}$; burst interval, 1-30 sec; firing frequency, 3-15 Hz). The APV-treated group had a lower incidence of spontaneous bursting but much longer burst durations than the control group (burst duration, 1-10 sec; burst interval, 1-30 sec; firing frequency, 3-20 Hz). 
A

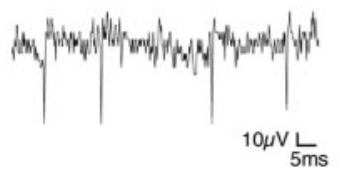

C

6 DIV

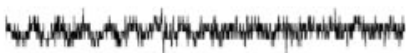

10 DIV

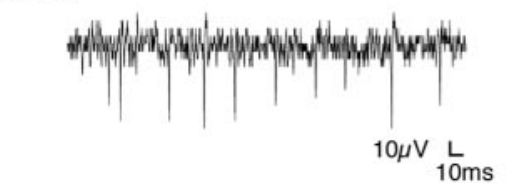

B

D
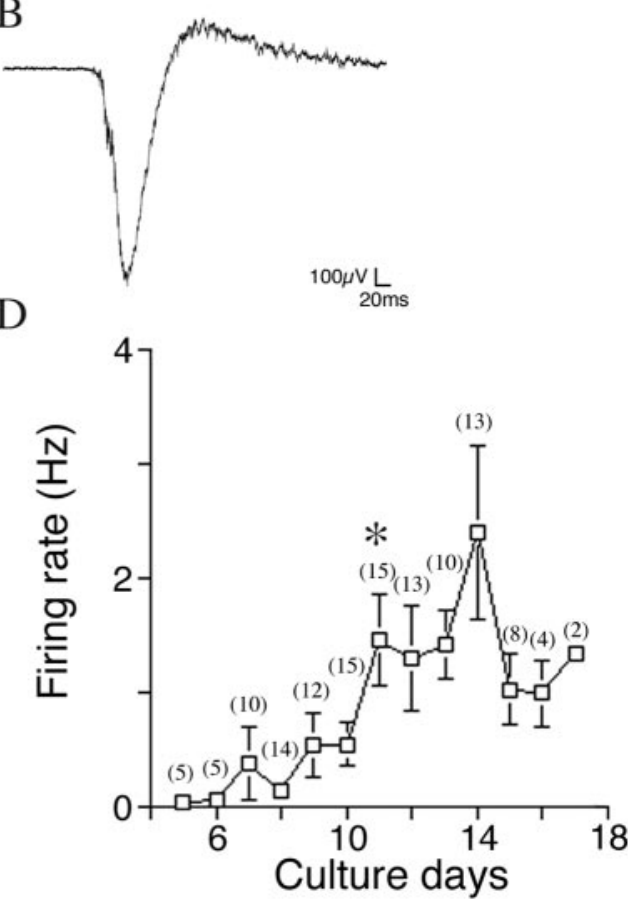

Figure 4. Development of spontaneous activity of cortical upper layer neurons. $A, B$, Examples of a voltage recording from a cultured cortical slice after 10 DIV. Single-unit activity $(A)$ and field potential-like activity $(B)$ are shown. $C$, Activity patterns recorded from the same slice after 6,10 , and 13 DIV are shown. D, The mean firing rates of spontaneous activity are shown as a function of culture days. Squares show the mean. Error bars represent SEM. The number in parentheses shows the sample number. The asterisk indicates a significant difference compared with the previous day (Mann-Whitney $U$ test; $p<0.05$ ).

A

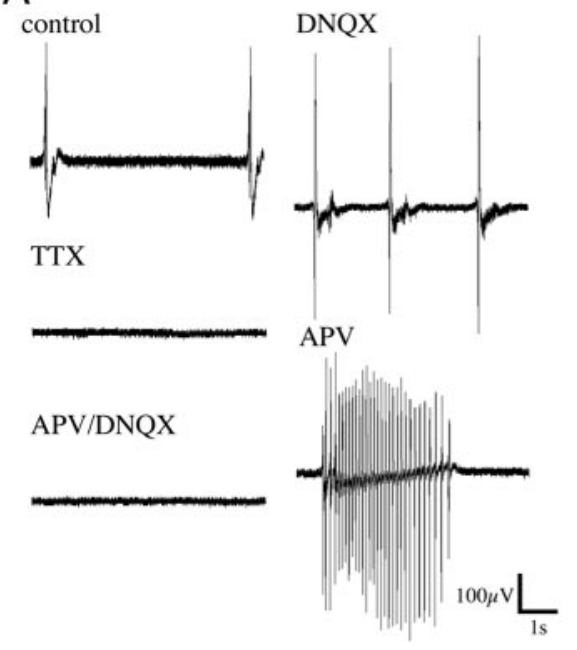

B

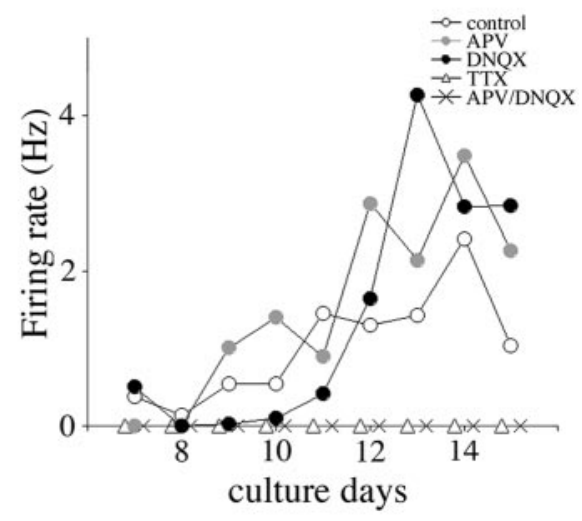

Figure 5. Effects of TTX, APV/DNQX, DNQX, or APV on spontaneous activity of upper layer cells. $A$, The typical patterns of spontaneous activity under control, TTX, APV/DNQX, DNQX, or APV treatments. Spontaneous activity after 12 DIV is shown. $B$, The mean firing rates of spontaneous activity in untreated and pharmacologically treated conditions are shown as a function of culture days.

Axonal branching at $13-15 \mathrm{~d}$ in cultures treated with these blockers was compared with controls. These pharmacological treatments did not appear to influence cell survival or the overall health of the cultures. Nissl-stained sections of the treated cultures (two to three slices for each treatment) revealed no differences in either cell size or density compared with control cultures (data not shown).

As shown in Figure 6, TTX, APV/ DNQX, and DNQX treatments each resulted in a decrease in branch number compared with control axons. The number of branch points is an index of the complexity of axonal branching. As described above, the mean number of branch points in untreated axons was $4.5 \pm 0.6$ $(n=42)$. Under TTX, APV/DNQX, and DNQX treatments, the number of branch points fell to one-third to one-half of the value in the untreated control group (Fig. 7A) (TTX: $2.1 \pm 0.7, n=14, p<0.05$; APV/DNQX: $1.5 \pm 0.4, n=11, p<0.05$; DNQX: $1.7 \pm 0.5, n=16, p<0.005)$. In contrast, APV did not cause a significant difference in branch number, which, if anything, was slightly increased (Fig. 7A) $(5.7 \pm 1.2 ; n=20 ; p>0.1)$.

To determine whether these decreases in the number of branch points were a simple consequence of differences in total arbor length, we calculated the density of branch points, defined as the number of branch points per $1 \mathrm{~mm}$ length. The mean density of branch points under control conditions was $3.3 \pm 0.4(n=42)$ branches per millimeter. TTX, APV/ DNQX, and DNQX decreased the density of branch points to nearly half that of controls (Fig. 7B) (TTX: $1.7 \pm 0.5, n=14$, $p<0.05$; APV/DNQX: $1.6 \pm 0.4, n=11$, $p<0.05$; DNQX: $1.91 \pm 0.3, n=16, p<$ 0.005). APV treatment did not affect branch density (Fig. $7 B)(4.4 \pm 1.2 ; n=20$; $p>0.1)$. These results indicate that the changes in the number of branch points cannot be attributed exclusively to a change in total arbor lengths.

It appeared that short branch tip segments were selectively lost in the TTX- or DNQX-treated axons (Fig. 6). As shown in Figure $7 C$, the mean branch tip segment length in TTX- and DNQX-treated axons was $303 \pm 69 \mu \mathrm{m}(n=43)$ and $306 \pm 70$ $\mu \mathrm{m}(n=40)$, respectively. They were significantly $(p<0.005$ and $p<0.05)$ larger than that in the controls $(109 \pm 12 \mu \mathrm{m}$; $n=233$ ). The average branch tip segment length in APV/DNQX treatment was also increased by approximately threefold, although this failed to reach statistical significance compared with controls (330 $\pm 128 \mu \mathrm{m} ; n=28 ; p>0.1)$ because of high variability in branch tip segment lengths. APV-treated axons showed no difference from controls ( $141 \pm 23 \mu \mathrm{m} ; n=131 ; p>0.1$ ).

We also examined the branch order of branch tip segments. As with the branch number and the branch density, the maximum order of branch tip segments under TTX, APV/DNQX, and DNQX treatments fell to one-third to one-half of the value in the untreated control group (control: $3.9 \pm 0.5, n=42$; TTX: $2.0 \pm$ 0.6, $n=14, p<0.05$; APV/DNQX: $1.4 \pm 0.3, n=11, p<0.01$; 


\section{TTX}

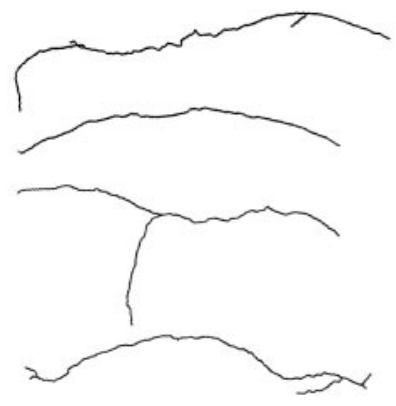

APV/DNQX

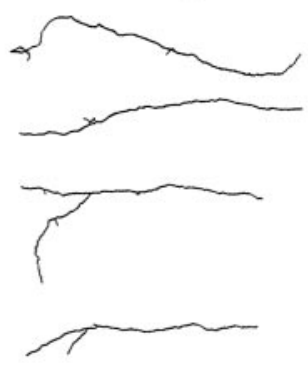

DNQX

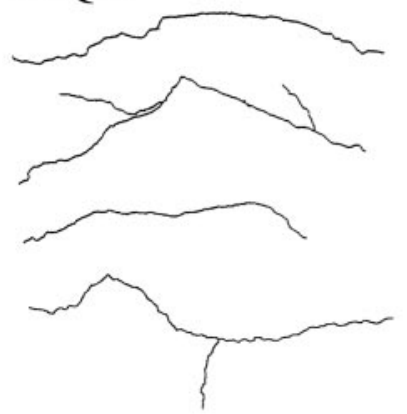

SYM2206

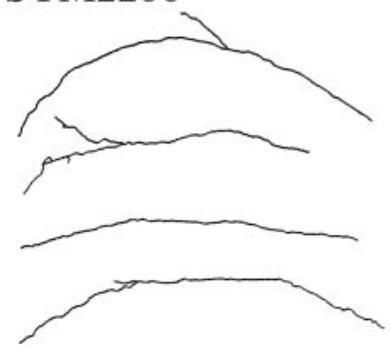

APV
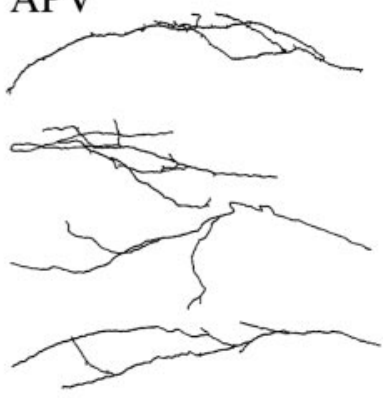

UBP301
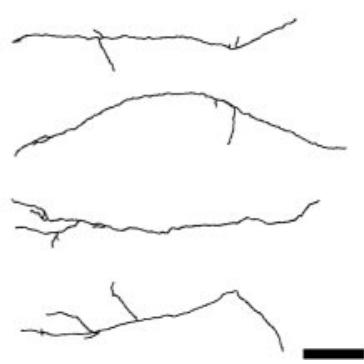

Figure 6. Axonal branching after 2 weeks in vitro under pharmacological treatments. Axonal branches in TTX-, APV/DNQX-, DNQX-, or SYM2206-treated slices appeared to decrease more than those of the control. In contrast, axonal branches under APV or UBP301 treatments tended not to be different from the control. Scale bar, $200 \mu \mathrm{m}$.

DNQX: $1.6 \pm 0.5, n=16, p<0.005)$. In contrast, APV did not cause a significant difference in the maximum branch order $(4.6 \pm 0.9 ; n=20 ; p>0.1)$.

One explanation for these results is that transmission through non-NMDA-type glutamate receptors exerts branch-promoting effects. To further examine this possibility, the specific and noncompetitive antagonist of AMPA receptors, SYM2206, or the potent kainate receptor antagonist UBP301 was added to the culture medium. Both drugs considerably reduced spontaneous activity, and this effect persisted to the final day of recording (the firing rate between 8 and 14 DIV: $0.15 \pm 0.09 \mathrm{~Hz} ; n=2$ for SYM2206; $0.34 \pm 0.09 \mathrm{~Hz} ; n=2$ for UBP301). Under these treatments, branch formation of horizontal axons was examined. SYM2206 treatment completely reduced the number of axonal branches and increased branch tip length, similar to that for DNQX treatment (branch number: $1.4 \pm 0.4, n=12, p<0.005$; branch density: $1.1 \pm 0.3, n=12, p<0.005$; branch tip segment length: $243 \pm 48 \mu \mathrm{m}, n=26, p<0.005$; maximum branch order: $1.3 \pm$ $0.3, n=12, p<0.01)$. In contrast, UBP301 treatment did not produce notable differences from control (branch number: $5.6 \pm 1.1, n=13, p>0.1$; branch density: $2.5 \pm 0.4, n=13$, $p>0.1$; maximum branch order: $4.2 \pm 0.7, n=12, p>0.1)$, except that tip segment length was slightly larger $(143 \pm 20$ $\mu \mathrm{m} ; n=85 ; p<0.05)$.

\section{Discussion}

Using an in vitro culture that preserves many properties of the intact brain, we have demonstrated that axons extending horizontally in the upper layers formed axonal arbors that were remarkably similar to those of horizontal axons in vivo. Electrophysiological recordings showed that the time of axonal branch emergence corresponded very closely to the onset of spontaneous activity. Moreover, blockade of spontaneous firing activity or non-NMDA transmission, but not NMDA transmission, resulted in decreased axonal branching. These findings suggest that firing activity, perhaps through the synaptic activation of nonNMDA receptors, in particular AMPA-type receptors, plays a role in promoting branch formation of horizontal axons.

\section{Comparison of axons of upper layer neurons in organotypic} slice cultures with horizontal axons in vivo

Previous studies have shown that neuronal migration, layer formation, cellular morphology, and physiology develop normally in cultured cortical explants (Yamamoto et al., 1989, 1992; Bolz et al., 1990, 1992; Molnar and Blakemore, 1991; Gotz and Bolz, 1992; Annis et al., 1993; Dantzker and Callaway, 1998). Similarly, individually YFP-labeled cells in our slice cultures exhibited a projection pattern and branch formation that is typical for layer $2 / 3$ cells in rodents (Lohmann and Rorig, 1994; van Brederode et al., 2000). These findings indicate that some intrinsic properties of upper layer neurons including branching properties and the surrounding cues including lamina-specific molecules are preserved and functional under culture conditions (Yamamoto et al., 1992, 1997, 2000; Yamamoto, 2002). As for axonal elongation, upper layer cell axons extended $1.5 \mathrm{~mm}$, on average, which is almost the same as that found in vivo (Burkhalter and Charles, 1990; Lohmann and Rorig, 1994; van Brederode et al., 2000). Thus, such intrinsic components might also regulate horizontal axon elongation, which might link functional columns as found in carnivores (Ts'o et al., 1986; Gilbert and Wiesel, 1989).

Neuronal activity in cultured cortical slices also seems to mature at a similar rate to that in vivo. Indeed, it has been reported that spontaneous firing is extremely rare in P7 cortical slices but increases at later stages to resemble the pattern of activity observed in the adult (Flint et al., 1997). Moreover, in freely moving rats, firing rates in the cortex increase to $\sim 1 \mathrm{~Hz}$ at P11 and P12 (Mirmiran and Corner, 1982). These similarities in developmental timing of spontaneous activity between the intact and cultured cortex suggest that intrinsic electrical properties such as membrane properties and the balance in the growth of inhibitory and excitatory systems also might be preserved in cultured cortical slices.

\section{Involvement of molecular cues in axonal branching of layer $2 / 3$ pyramidal neurons}

The fact that a small number of branches still form in the absence of synaptic transmission or action potentials indicates that some factors independent of neuronal activity also contribute to branch formation of horizontal axons (Dantzker and Callaway, 1998; Borrell and Callaway, 2002). For example, a branchinducing factor may be expressed in the upper layers that acts on horizontal axons (Yamamoto, 2002). For cortical circuitry, it has been reported that ephrin-A5 is expressed in the middle layer, where it promotes branching of layer 6 neurons (Castellani et al., 
A

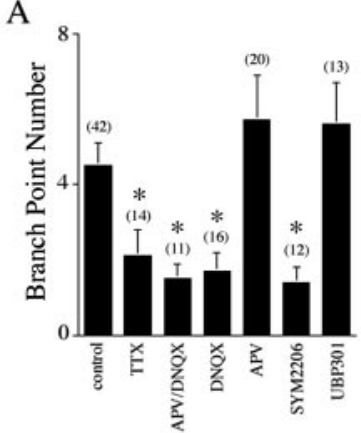

B

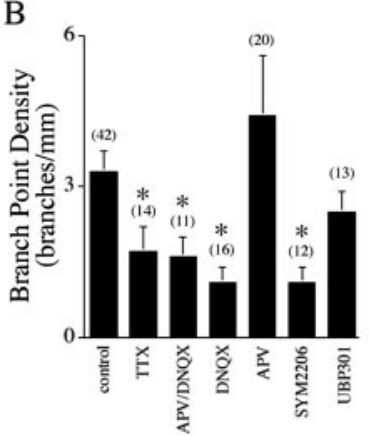

$\mathrm{C}$

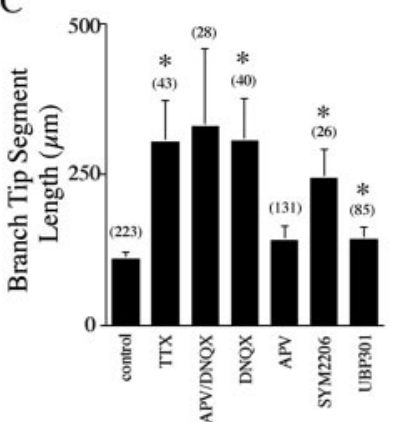

Figure 7. Quantitative analysis of axonal arbors under various drug treatments. Changes in the number of branch points $(A)$, branch point density $(B)$, and branch tip segment length $(C$ are shown. The number of axons analyzed $(A, B)$ and the number of branch tips $(C)$ in each case are in parentheses. Bars illustrate the mean \pm SEM. Asterisks indicate a significant difference from control (Mann-Whitney $U$ test; $p<0.05$ ).

1998). Szebenyi et al. (2001) have demonstrated that FGF-2 induces axonal branches from cortical neurons, although its expression pattern is not known in vivo. Thus, such branchpromoting factors for horizontal axons would be predicted to be upregulated starting the second postnatal week. It is also possible that intrinsic properties of upper layer neurons, such as axonal length or developmental timing, influence branching in a cellautonomous manner (Szebenyi et al., 1998).

\section{Dynamics of axonal branching}

The present study is the first to demonstrate dynamic remodeling of axon terminal arbors in the mammalian brain, although a similar mode of axonal arborization has been seen in fish and frog retinotectal projections (O’Rourke and Fraser, 1990; Kaethner and Stuermer, 1992; O'Rourke et al., 1994; Cohen-Cory, 1999). In the retinotectal system as well as in our study, a larger proportion of branches were observed undergoing addition than retraction, although the exact proportion of branches added or lost differs between cortical and retinal axons (O'Rourke and Fraser, 1990; O'Rourke et al., 1994). This difference reflects the numerous differences between these systems, including temperature, locally expressed branching factors, and intrinsic properties of the neurons themselves.

The dynamic branching of axonal arbors may correlate with the formation of synapses with target cells. In the Xenopus visual system, it was demonstrated that as axons arborized, new synapses appeared rapidly and that axonal branch points were preferentially located at synaptic sites (Alsina et al., 2001). In our study, axonal varicosities, which are thought to reflect synapses, were present along the axons (Fig. $2 \mathrm{~A}$ ). Furthermore, the number of varicosities correlated positively with the number of branch points at least in those axons on which swellings were clearly observed (data not shown). These results suggest that dynamic branch formation could reflect changes in synaptic connectivity and that presynaptic and postsynaptic interactions through firing and synaptic activity may affect branching.

\section{Possible mechanism of activity-dependent axonal branching} Our results show that suppression of neuronal activity, specifically synaptic activity through AMPA receptors, inhibits branch formation, including the branch number and the branch length. This finding contrasts with numerous observations in vivo in which activity blockade causes an expansion of axonal arbors in retinotectal (Cohen-Cory, 1999), retinogeniculate (Sretavan et al., 1988), and thalamocortical projections (Antonini and
Stryker, 1993). Although laminar organization, synaptic maturation, and neuronal excitability in our organotypic culture closely mimics that in the intact brain, one aspect that distinguishes our preparation from the in vivo condition is the absence of external topographic inputs driven directly or indirectly by the sensory periphery. Therefore, it is reasonable to infer that activity blockade in vivo would interfere with activity-dependent competitive interactions. In contrast, horizontally extending cortical axons in our cultures, which have highly synchronized firing over long distances, exhibit activity patterns that may be less likely to favor competitive interactions. Different firing patterns of activity are likely to have different effects on neural circuitry (Itoh et al., 1997), especially in situations in which patterned activity might promote competition among inputs (Crair, 1999). It has been reported that neural activity affects dendritic branching as well (McAllister et al., 1996). Interestingly, activity blockade has been reported in the retinotectal system to produce different effects on axonal and dendritic dynamics, consistent with the differences between our data on axon morphology and published data on dendrites (Rajan and Cline, 1998; Rajan et al., 1999).

One surprising result was that chronic pharmacological blockade of AMPA-type glutamate receptors, but not of NMDA receptors, reduced the number of axonal branch points by an amount comparable with activity blockade by TTX or APV/ DNQX treatment. Importantly, our use of MED recordings of cultures treated chronically with APV or DNQX revealed in both cases a homeostatic recovery of spontaneous activity to control levels within $\sim 5 \mathrm{~d}$. Thus, the failure of axon arbors to branch extensively when AMPA receptors are selectively blocked cannot be attributed to a lack of spontaneous activity in these cultures. Furthermore, treatment with MK-801, another antagonist of NMDA receptors, like APV did not cause a significant change in branch point number or in mean branch tip segment length compared with untreated controls (data not shown). These observations support the view that neuronal activity increases branch formation by causing synaptic transmission through nonNMDA receptors.

Although these data support a key role for AMPA receptor activation in horizontal axon branching, they do not entirely preclude the participation of NMDA receptors in this process. NMDA receptors could work in a coordinated manner with non-NMDA receptors. For example, if the primary contribution of the NMDA receptors in axonal morphogenesis were to cause branch elimination under conditions of weak NMDA receptor activation, as occurs at hyperpolarized potentials, AMPA receptor blockade could promote this. Nonetheless, the fact that DNQX (or SYM2206) alone is as effective as the combined application of DNQX and APV at reducing branch complexity suggests that AMPA receptor activation is specifically required for proper axonal branching.

There is considerable evidence that NMDA receptors are required for certain aspects of development and topographic refinement of axonal arbors (Cline and Constantine-Paton, 1990; O’Rourke et al., 1994; Mitrovic et al., 1996; Rajan et al., 1999; Ruthazer et al., 2003). For example, retinal axons from two eyes, made to innervate the same optic tectal lobe in frogs, segregate 
during development, but this segregation can be abolished by blockade of NMDA receptors (Cline and Constantine-Paton, 1990). Suppression of NMDA receptor function also prevents the development of orientation selectivity in the visual cortex ( $\mathrm{Ra}-$ moa et al., 2001), a property that correlates anatomically and developmentally with the structural development of horizontal axons (Lowel and Singer, 1992; Ruthazer and Stryker, 1996). However, we found that blocking spontaneous non-NMDA receptor activation rather than NMDA receptor activation dramatically reduced axonal branching of cortical upper layer neurons during their initial period of branch formation. These results support the idea that NMDA receptors may play different anatomical and functional roles in different systems (Fox et al., 1989; Smetters et al., 1994; Hahm et al., 1999; Yamada et al., 2000).

An alternative possibility involves calcium influx through AMPA receptors, which may be critical for guiding neural circuit formation in the mammalian CNS (Katz and Shatz, 1996; Gomez and Spitzer, 2000; Chang and De Camilli, 2001; Tashiro et al., 2003). AMPA receptor activation could cause a depolarization, which in turn might open a voltage-dependent calcium channel (VDCC). Furthermore, it has been shown that AMPA receptors lacking glutamate receptor 2 are highly permeable to calcium (Hollmann et al., 1991; Verdoorn et al., 1991). It has been suggested that calcium-permeable AMPA receptors could induce NMDA receptor-independent long-term potentiation, which might contribute to neural circuit formation (Jia et al., 1996). Therefore, calcium entry through VDCC or calcium-permeable AMPA receptors could participate directly in activity-dependent remodeling of horizontal axons.

\section{References}

Acebes A, Ferrus A (2000) Cellular and molecular features of axon collaterals and dendrites. Trends Neurosci 23:557-565.

Alsina B, Vu T, Cohen-Cory S (2001) Visualizing synapse formation in arborizing optic axons in vivo: dynamics and modulation by BDNF. Nat Neurosci 4:1093-1101.

Annis CM, Robertson RT, O’Dowd DK (1993) Aspects of early postnatal development of cortical neurons that proceed independently of normally present extrinsic influences. J Neurobiol 24:1460-1480.

Antonini A, Stryker MP (1993) Development of individual geniculocortical arbors in cat striate cortex and effects of binocular impulse blockade. J Neurosci 13:3549-3573.

Antonini A, Stryker MP (1996) Plasticity of geniculocortical afferents following brief or prolonged monocular occlusion in the cat. J Comp Neurol 369:64-82.

Antonini A, Fagiolini M, Stryker MP (1999) Anatomical correlates of functional plasticity in mouse visual cortex. J Neurosci 19:4388-4406.

Bolz J, Novak N, Gotz M, Bonhoeffer T (1990) Formation of target-specific neuronal projections in organotypic slice cultures from rat visual cortex. Nature 346:359-362.

Bolz J, Novak N, Staiger V (1992) Formation of specific afferent connections in organotypic slice cultures from rat visual cortex cocultured with lateral geniculate nucleus. J Neurosci 12:3054-3070.

Borrell V, Callaway EM (2002) Reorganization of exuberant axonal arbors contributes to the development of laminar specificity in ferret visual cortex. J Neurosci 22:6682-6695.

Burkhalter A, Charles V (1990) Organization of local axon collaterals of efferent projection neurons in rat visual cortex. J Comp Neurol 302:920-934.

Callaway EM, Katz LC (1990) Emergence and refinement of clustered horizontal connections in cat striate cortex. J Neurosci 10:1134-1153.

Callaway EM, Katz LC (1991) Effects of binocular deprivation on the development of clustered horizontal connections in cat striate cortex. Proc Natl Acad Sci USA 88:745-749.

Castellani V, Yue Y, Gao PP, Zhou R, Bolz J (1998) Dual action of a ligand for Eph receptor tyrosine kinases on specific populations of axons during the development of cortical circuits. J Neurosci 18:4663-4672.
Chang S, De Camilli P (2001) Glutamate regulates actin-based motility in axonal filopodia. Nat Neurosci 4:787-793.

Cline HT, Constantine-Paton M (1990) NMDA receptor agonist and antagonists alter retinal ganglion cell arbor structure in the developing frog retinotectal projection. J Neurosci 10:1197-1216.

Cohen-Cory S (1999) BDNF modulates, but does not mediate, activitydependent branching and remodeling of optic axon arbors in vivo. J Neurosci 19:9996-10003.

Crair MC (1999) Neuronal activity during development: permissive or instructive? Curr Opin Neurobiol 9:88-93.

Dantzker JL, Callaway EM (1998) The development of local, layer-specific visual cortical axons in the absence of extrinsic influences and intrinsic activity. J Neurosci 18:4145-4154.

Durack JC, Katz LC (1996) Development of horizontal projections in layer 2/3 of ferret visual cortex. Cereb Cortex 6:178-183.

Flint AC, Maisch US, Kriegstein AR (1997) Postnatal development of low $\left[\mathrm{Mg}^{2+}\right]$ oscillations in neocortex. J Neurophysiol 78:1990-1996.

Fox K, Sato H, Daw N (1989) The location and function of NMDA receptors in cat and kitten visual cortex. J Neurosci 9:2443-2454.

Gilbert CD, Wiesel TN (1979) Morphology and intracortical projections of functionally characterised neurones in the cat visual cortex. Nature 280:120-125.

Gilbert CD, Wiesel TN (1989) Columnar specificity of intrinsic horizontal and corticocortical connections in cat visual cortex. J Neurosci 9:2432-2442.

Gomez TM, Spitzer NC (2000) Regulation of growth cone behavior by calcium: new dynamics to earlier perspectives. J Neurobiol 44:174-183.

Gotz M, Bolz J (1992) Formation and preservation of cortical layers in slice cultures. J Neurobiol 23:783-802.

Haas K, Sin WC, Javaherian A, Li Z, Cline HT (2001) Single-cell electroporation for gene transfer in vivo. Neuron 29:583-591.

Hahm JO, Cramer KS, Sur M (1999) Pattern formation by retinal afferents in the ferret lateral geniculate nucleus: developmental segregation and the role of $N$-methyl-D-aspartate receptors. J Comp Neurol 411:327-345.

Hata Y, Stryker MP (1994) Control of thalamocortical afferent rearrangement by postsynaptic activity in developing visual cortex. Science 265:1732-1735.

Hata Y, Tsumoto T, Stryker MP (1999) Selective pruning of more active afferents when cat visual cortex is pharmacologically inhibited. Neuron 22:375-381.

Hindges R, McLaughlin T, Genoud N, Henkemeyer M, O’Leary DD (2002) EphB forward signaling controls directional branch extension and arborization required for dorsal-ventral retinotopic mapping. Neuron 35:475-487.

Hollmann M, Hartley M, Heinemann S (1991) $\mathrm{Ca}^{2+}$ permeability of KAAMPA-gated glutamate receptor channels depends on subunit composition. Science 252:851-853.

Hubel DH, Wiesel TN, LeVay S (1977) Plasticity of ocular dominance columns in monkey striate cortex. Philos Trans R Soc Lond B Biol Sci 278:377-409.

Inoue A, Sanes JR (1997) Lamina-specific connectivity in the brain: regulation by $\mathrm{N}$-cadherin, neurotrophins, and glycoconjugates. Science 276:1428-1431.

Itoh K, Ozaki M, Stevens B, Fields RD (1997) Activity-dependent regulation of N-cadherin in DRG neurons: differential regulation of N-cadherin, NCAM, and L1 by distinct patterns of action potentials. J Neurobiol 33:735-748.

Jia Z, Agopyan N, Miu P, Xiong Z, Henderson J, Gerlai R, Taverna FA, Velumian A, MacDonald J, Carlen P, Abramow-Newerly W, Roder J (1996) Enhanced LTP in mice deficient in the AMPA receptor GluR2. Neuron 17:945-956.

Kaethner RJ, Stuermer CA (1992) Dynamics of terminal arbor formation and target approach of retinotectal axons in living zebrafish embryos: a time-lapse study of single axons. J Neurosci 12:3257-3271.

Katz LC, Shatz CJ (1996) Synaptic activity and the construction of cortical circuits. Science 274:1133-1138.

Lohmann H, Rorig B (1994) Long-range horizontal connections between supragranular pyramidal cells in the extrastriate visual cortex of the rat. J Comp Neurol 344:543-558.

Lowel S, Singer W (1992) Selection of intrinsic horizontal connections in the visual cortex by correlated neuronal activity. Science 255:209-212.

Luthi A, Schwyzer L, Mateos JM, Gahwiler BH, McKinney RA (2001) 
NMDA receptor activation limits the number of synaptic connections during hippocampal development. Nat Neurosci 4:1102-1107.

Mann F, Peuckert C, Dehner F, Zhou R, Bolz J (2002) Ephrins regulate the formation of terminal axonal arbors during the development of thalamocortical projections. Development 129:3945-3955.

McAllister AK, Lo DC, Katz LC (1995) Neurotrophins regulate dendritic growth in developing visual cortex. Neuron 15:791-803.

McAllister AK, Katz LC, Lo DC (1996) Neurotrophin regulation of cortical dendritic growth requires activity. Neuron 17:1057-1064.

McGuire BA, Gilbert CD, Rivlin PK, Wiesel TN (1991) Targets of horizontal connections in macaque primary visual cortex. J Comp Neurol 305:370-392.

McLaughlin T, Hindges R, O'Leary DD (2003a) Regulation of axial patterning of the retina and its topographic mapping in the brain. Curr Opin Neurobiol 13:57-69.

McLaughlin T, Hindges R, Yates PA, O'Leary DD (2003b) Bifunctional action of ephrin-B1 as a repellent and attractant to control bidirectional branch extension in dorsal-ventral retinotopic mapping. Development 130:2407-2418

Mirmiran M, Corner M (1982) Neuronal discharge patterns in the occipital cortex of developing rats during active and quiet sleep. Brain Res 255:37-48.

Mitrovic N, Mohajeri H, Schachner M (1996) Effects of NMDA receptor blockade in the developing rat somatosensory cortex on the expression of the glia-derived extracellular matrix glycoprotein tenascin-C. Eur J Neurosci 8:1793-1802.

Molnar Z, Blakemore C (1991) Lack of regional specificity for connections formed between thalamus and cortex in coculture. Nature 351:475-477.

Niwa H, Yamamura K, Miyazaki J (1991) Efficient selection for highexpression transfectants with a novel eukaryotic vector. Gene 108:193-199.

O’Rourke NA, Fraser SE (1990) Dynamic changes in optic fiber terminal arbors lead to retinotopic map formation: an in vivo confocal microscopic study. Neuron 5:159-171.

O’Rourke NA, Cline HT, Fraser SE (1994) Rapid remodeling of retinal arbors in the tectum with and without blockade of synaptic transmission. Neuron 12:921-934.

Penn AA, Riquelme PA, Feller MB, Shatz CJ (1998) Competition in retinogeniculate patterning driven by spontaneous activity. Science 279: $2108-2112$.

Rajan I, Cline HT (1998) Glutamate receptor activity is required for normal development of tectal cell dendrites in vivo. J Neurosci 18:7836-7846.

Rajan I, Witte S, Cline HT (1999) NMDA receptor activity stabilizes presynaptic retinotectal axons and postsynaptic optic tectal cell dendrites in vivo. J Neurobiol 38:357-368.

Ramoa AS, Mower AF, Liao D, Jafri SI (2001) Suppression of cortical NMDA receptor function prevents development of orientation selectivity in the primary visual cortex. J Neurosci 21:4299-4309.

Reh TA, Constantine-Paton M (1985) Eye-specific segregation requires neural activity in three-eyed Rana pipiens. J Neurosci 5:1132-1143.

Roberts JS, O'Rourke NA, McConnell SK (1993) Cell migration in cultured cerebral cortical slices. Dev Biol 155:396-408.

Rockland KS, Lund JS (1982) Widespread periodic intrinsic connections in the tree shrew visual cortex. Science 215:1532-1534.

Ruthazer ES, Stryker MP (1996) The role of activity in the development of long-range horizontal connections in area 17 of the ferret. J Neurosci 16:7253-7269.

Ruthazer ES, Akerman CJ, Cline HT (2003) Control of axon branch dynamics by correlated activity in vivo. Science 301:66-70.

Sakurai T, Wong E, Drescher U, Tanaka H, Jay DG (2002) Ephrin-A5 restricts topographically specific arborization in the chick retinotectal projection in vivo. Proc Natl Acad Sci USA 99:10795-10800.

Sanes JR, Yamagata M (1999) Formation of lamina-specific synaptic connections. Curr Opin Neurobiol 9:79-87.
Shatz CJ, Stryker MP (1988) Prenatal tetrodotoxin infusion blocks segregation of retinogeniculate afferents. Science 242:87-89.

Shimono K, Baudry M, Panchenko V, Taketani M (2002) Chronic multichannel recordings from organotypic hippocampal slice cultures: protection from excitotoxic effects of NMDA by non-competitive NMDA antagonists. J Neurosci Methods 120:193-202.

Smetters DK, Hahm J, Sur M (1994) An N-methyl-D-aspartate receptor antagonist does not prevent eye-specific segregation in the ferret retinogeniculate pathway. Brain Res 658:168-178.

Sretavan DW, Shatz CJ, Stryker MP (1988) Modification of retinal ganglion cell axon morphology by prenatal infusion of tetrodotoxin. Nature 336:468-471.

Szebenyi G, Callaway JL, Dent EW, Kalil K (1998) Interstitial branches develop from active regions of the axon demarcated by the primary growth cone during pausing behaviors. J Neurosci 18:7930-7940.

Szebenyi G, Dent EW, Callaway JL, Seys C, Lueth H, Kalil K (2001) Fibroblast growth factor-2 promotes axon branching of cortical neurons by influencing morphology and behavior of the primary growth cone. J Neurosci 21:3932-3941.

Tashiro A, Dunaevsky A, Blazeski R, Mason CA, Yuste R (2003) Bidirectional regulation of hippocampal mossy fiber filopodial motility by kainate receptors: a two-step model of synaptogenesis. Neuron 38:773-784

Ts'o DY, Gilbert CD, Wiesel TN (1986) Relationships between horizontal interactions and functional architecture in cat striate cortex as revealed by cross-correlation analysis. J Neurosci 6:1160-1170.

Turrigiano GG, Leslie KR, Desai NS, Rutherford LC, Nelson SB (1998) Activity-dependent scaling of quantal amplitude in neocortical neurons. Nature 391:892-896.

Udin SB (1983) Abnormal visual input leads to development of abnormal axon trajectories in frogs. Nature 301:336-338.

van Brederode JF, Foehring RC, Spain WJ (2000) Morphological and electrophysiological properties of atypically oriented layer 2 pyramidal cells of the juvenile rat neocortex. Neuroscience 101:851-861.

Verdoorn TA, Burnashev N, Monyer H, Seeburg PH, Sakmann B (1991) Structural determinants of ion flow through recombinant glutamate receptor channels. Science 252:1715-1718.

Yamada K, Yamamoto N, Toyama K (2000) Development of NMDA and non-NMDA receptor-mediated excitatory synaptic transmission in geniculocortical and corticocortical connections in organotypic coculture preparations. Eur J Neurosci 12:3854-3862.

Yamagata M, Sanes JR (1995) Lamina-specific cues guide outgrowth and arborization of retinal axons in the optic tectum. Development $121: 189-200$

Yamamoto N (2002) Cellular and molecular basis for the formation of lamina-specific thalamocortical projections. Neurosci Res 42:167-173.

Yamamoto N, Kurotani T, Toyama K (1989) Neural connections between the lateral geniculate nucleus and visual cortex in vitro. Science 245:192-194.

Yamamoto N, Yamada K, Kurotani T, Toyama K (1992) Laminar specificity of extrinsic cortical connections studied in coculture preparations. Neuron 9:217-228.

Yamamoto N, Higashi S, Toyama K (1997) Stop and branch behaviors of geniculocortical axons: a time-lapse study in organotypic cocultures. J Neurosci 17:3653-3663.

Yamamoto N, Inui K, Matsuyama Y, Harada A, Hanamura K, Murakami F, Ruthazer ES, Rutishauser U, Seki T (2000) Inhibitory mechanism by polysialic acid for lamina-specific branch formation of thalamocortical axons. J Neurosci 20:9145-9151.

Yamamoto N, Tamada A, Murakami F (2002) Wiring of the brain by a range of guidance cues. Prog Neurobiol 68:393-407.

Yates PA, Roskies AL, McLaughlin T, O'Leary DD (2001) Topographicspecific axon branching controlled by ephrin-As is the critical event in retinotectal map development. J Neurosci 21:8548-8563. 